\title{
La viruela en México: historia de continuidades y rupturas en su control, prevención y erradicación, 1870-1950
}

\author{
Smallpox in Mexico: a history of continuities and ruptures \\ in its control, prevention and eradication, 1870-1950
}

\author{
América Molina del Villar \\ Investigadora, Centro de Investigaciones y Estudios Superiores en Antropología Social, Ciudad de México. \\ avillar@ciesas.edu.mx
}

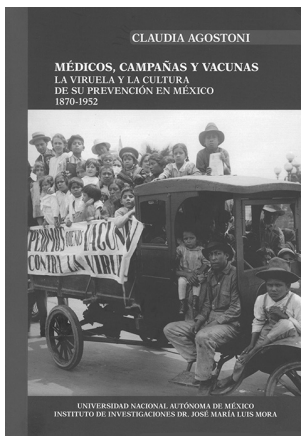

AGOSTONI, Claudia. Médicos, campañasy vacunas: la viruela y la cultura de su prevención en México, 1870-1952. México: Universidad Nacional Autónoma de México. 2016. 240p.
A raíz de la llegada de los españoles al Nuevo Mundo, la viruela poblaciones americanas. Desde el siglo XVI, ya fuera por tierra o mar, esta enfermedad se fue diseminando en las poblaciones descubiertas y colonizadas por frailes, colonizadores y conquistadores. En el transcurso de los siglos XVIII y XIX, la viruela, con distinto grado de intensidad, continuó causando estragos en la población, principalmente en los niños y jóvenes. Sin embargo, a fines del siglo XVIII habría un cambio importante en la manera de combatir y evitar el impacto de esta enfermedad. En 1796, en Inglaterra, Eduardo Jenner descubrió la vacuna antivariólica utilizando la secreción de las pústulas de las vacas (cow pox). Dos años después, en un texto titulado An inquiry into the causes and effects of variolare vaccinae, Jenner proponía otro método para prevenir este padecimiento, que consistía en la introducción, en personas sanas, del pus extraído de las ubres de las vacas, provocando cierta inmunización en el individuo. Se trató de un gran descubrimiento que alcanzó gran difusión en el mundo. En España, Carlos IV autorizó la organización de la Real Expedición Filantrópica de la Vacuna, que partió de La Coruña en diciembre de 1803, cuya intención era librar de esta terrible enfermedad a las poblaciones americanas. En dicha expedición iban vinte niños, en cuyas pústulas traían el fluido vacunal o bien éste fue transportado en láminas de vidrio. La expedición estuvo al mando de Francisco Xavier Balmis, quien se dirigió a México y de José Salvany, que se fue a Colombia, Ecuador y Perú (Ramírez Martin, 2001).

El alcance o éxito de dichas campañas de variolización o inoculación no dejaron de estar al margen de críticas, pues en ocasiones este procedimiento podía provocar "viruelas artificiales", es decir brotes de la misma enfermedad. De tal suerte que estas prácticas de prevención 
originaron incertidumbre, miedo o rechazo. Es precisamente en el nivel de las ideas médicas, reacciones sociales y actuación de las autoridades que se valora el gran aporte del libro de Claudia Agostoni, Médicos, campañas y vacunas. La viruela y la cultura de su prevención en México, 1870-1952, cuyos ejes de análisis son innovadores y constituyen una gran contribución a la historia de la salud pública en México en el siglo XX. Cabe decir que la viruela continuó manifestándose a lo largo de los siglos XIX y XX, cuyo impacto se agravaba por la situación de crisis económica y social. En este sentido, el estudio de Agostoni es revelador en tanto contextualiza los logros y fracasos en la historia de las campañas de salud, así como de la actuación de los médicos y del Estado para prevenir, controlar y erradicar la viruela en México. El periodo analizado en esta obra marca cambios sociales y económicos significativos: la caída del antiguo régimen porfirista, los años convulsionados de la Revolución Mexicana, la lucha de las facciones políticas por el control del país y el fortalecimiento de los gobiernos posrevolucionarios. Este contexto histórico, sin duda, fue delineando los avatares en torno al control y prevención de la viruela en el país. A lo largo de cinco capítulos la autora se adentra a analizar varios temas: los debates e incertidumbres en la prevención de la viruela; el papel de las instituciones de gobierno; la obligatoriedad de la vacunación; las posiciones confrontadas de los médicos y el surgimiento de la medicina rural y social durante las décadas de 1940 y 1950. En el periodo analizado ocurrió un cambio importante en materia de campañas de salud, ya que de un modelo militar, de control social y obligatoriedad de las campañas de vacunación se transmuta a campañas de persuasión y educación. También es importante destacar el último capítulo del libro dedicado al desarrollo de una medicina social centrada en combatir la pobreza en el medio rural, zona constantemente azotada por las enfermedades infecciosas y que estaba muy rezagada en materia de asistencia y salubridad pública.

En el afán de control, prevención y erradicación de la viruela se observa a una sociedad que actuó y no se mantuvo pasiva. La autora se detiene a analizar algunos casos, como el del niño Fidencio y de la actuación de algunos padres de familia que se opusieron a ciertas campañas de vacunación y detección de la difteria y escarlatina. Estos casos muestran otra dimensión de cómo la sociedad afrontaba sus problemas de salud y actuaba para prevenirlos; una realidad presente en nuestros días. Otro logro del trabajo es analizar con detalle cómo en esta etapa se fue gestando una cultura generalizada de prevención ante padecimientos que se podían evitar con la vacunación, la cual fue dirigida por múltiples actores sociales. El libro, además, va acompañado de bellas fotografías que ilustran a una sociedad comprometida con las campañas de vacunación a través de la educación. Una valiosa y rica documentación de archivo sustenta la investigación. Informes, cartas y expedientes del Archivo Histórico de la Secretaria de Salud, del Archivo de la Fundación Bustamante Vasconcelos, de la Secretaría de Educación Pública y del Archivo Histórico del Distrito Federal, así como prensa, bibliografía especializada y artículos científicos de la época.

Finalmente concluyo con consideraciones a la obra. Una reflexión en torno a la comparación que pudo adquirir este modelo de prevención y erradicación con respecto a otros padecimientos igualmente mortíferos, como sífilis, tifo y fiebre amarilla. Del mismo modo, discutir hasta qué punto la centralización en materia de salud pública fue aceptada o cuestionada por autoridades de otros ámbitos, ayuntamiento y gobiernos locales. Es decir, 
la manera cómo estas campañas promovidas desde el gobierno federal fueron aterrizadas a nivel local en otros espacios no considerados, tema para futuras investigaciones.

\section{REFERENCIA}

RAMÍREZ MARTÍN, Susana.

La salud del Imperio: la Real Expedición

Filantrópica de la Vacuna. Madrid: Fundación

Jorge Juan. 2001. 